\title{
Molecular evidence that Heligmosomoides polygyrus from laboratory mice and wood mice are separate species
}

\author{
J. CABLE ${ }^{1 *}$, P. D. HARRIS ${ }^{2}$ J. W. LEWIS ${ }^{3}$ and J. M. BEHNKE ${ }^{2}$ \\ ${ }^{1}$ School of Biosciences, Cardiff University, Cardiff CF10 3TL, UK \\ ${ }^{2}$ School of Biology, University of Nottingham, Nottingham NG7 2RD, UK \\ ${ }^{3}$ School of Biological Sciences, Royal Holloway, University of London, Egham, Surrey TW20 OEX, UK
}

(Received 23 Fuly 2005; revised 9 November 2005 and 16 Fanuary 2006; accepted 16 Fanuary 2006; first published online 15 March 2006)

\section{SUMMARY}

The gastro-intestinal (GI) nematode Heligmosomoides polygyrus is an important experimental model in laboratory mice and a well-studied parasite of wood mice in the field. Despite an extensive literature, the taxonomy of this parasite in different hosts is confused, and it is unclear whether laboratory and field systems represent the same or different Operational Taxonomic Units (OTUs). Molecular analyses reveal high sequence divergence between H. p. bakeri (laboratory) and H.p.polygyrus (field); $3 \%$ difference in the ribosomal DNA Internal Transcribed Spacers (ITS) and $8 \cdot 6 \%$ variation in the more rapidly evolving mitochondrial cytochrome c oxidase I (COI) gene. The COI sequence of U.K. H. p. polygyrus is more similar to $H$. glareoli from voles than to $H$.p. bakeri, while a single isolate of $H$. p.polygyrus from Guernsey confirms the extent of genetic variation between $H$. p. polygyrus populations. Analysis of molecular variance demonstrated that mtCOI sequence variation is associated primarily with groups with distinct ITS2 sequences, and with host identity, but is not partitioned significantly with a single combined taxon $H$. polygyrus incorporating European and North American isolates. We conclude therefore that the laboratory OTU should be raised to the level of a distinct species, as $H$. bakeri from the laboratory mouse Mus musculus, and we reject the hypothesis that $H$. bakeri has diverged from H.polygyrus in the recent past following introduction into America. However, we are unable to reject the hypothesis that $H$.polygyrus and $H$. bakeri are sister taxa, and it may be that $H$. polygyrus is polyphyletic or paraphyletic.

Key words: heligmosomatid, Apodemus sylvaticus, GI nematodes.

\section{INTRODUCTION}

At the species level debate over precise boundaries is critical, not least for practical reasons (Sites and Marshall, 2004). This is particularly so where an organism has become an established and important model for phenomena of more general medical and veterinary importance. Heligmosomoides polygyrus, a paradigm for chronic gastro-intestinal (GI) nematode infections, has been the subject of controversy over its specific identity since first isolated by Ehrenford in the $1950 \mathrm{~s}$. The parasite in culture originated from an abnormal infection of Peromyscus maniculatus (deer mouse) in North America (see Forrester and Nielson, 1973). The parasite was then established in laboratory mice, and disseminated throughout the world as a model system for teaching and research (Behnke et al. 1991). This system, based on a single isolation, has been widely used for screening potential anthelminthics (Burg and Stapley, 1989), and as a convenient, manipulable model for investigating the immunology of chronic intestinal nematode infections, such as those caused

* Corresponding author: School of Biosciences, Cardiff University, Cardiff CF10 3TL, UK. Tel: 0044292 0876022. Fax: 0044292 0874305. E-mail: cablej@cardiff. ac.uk by hookworms in Man and trichostrongyloid nematodes in domestic livestock (Keymer and Slater, 1990; Scott and Tanguay, 1994). For more than 4 decades, it has been the paradigm for immunosuppression by GI nematodes as a strategy facilitating chronic infections in mammalian hosts (e.g. Behnke, 1987; Monroy and Enriquez, 1992). Parasite-induced modification of host behaviour has provided an additional fertile field of investigation (Behnke, 1987; Barnard et al. 1998; Kavaliers et al. 2003).

The worm from Peromyscus was virtually identical to an Old World nematode, Heligmosomoides polygyrus, a dominant helminth in the Eurasian field or wood mouse Apodemus sylvaticus (see Behnke et al. 1991 for a review of the early taxonomic history of this worm). The life-history traits and ecology of this Operational Taxonomic Unit (OTU) have been explored extensively (Gregory et al. 1992; Quinnell, 1992; Abu-Madi et al. 1998, 2000 a; Behnke et al. 1999). Durette-Desset et al. (1972) considered the American worms $(H$. p. bakeri) to be a sister subspecies to the European OTU (H. p. polygyrus), a relationship which implies a potential for genetic interchange and continuity of biology between the two taxa. This view was upheld by Behnke et al. (1991) and the subspecies have since been elevated to species (Tenora and Barus, 2001; Tenora et al. 
2003; evidence from the latter appeared to be largely derived from a personal communication from Behnke, summarizing the observations presented in the current paper, indicating that molecular evidence supported separate species status for these taxa). However, the most important question remains unanswered: Is the OTU H. polygyrus (polygyrus), the dominant endemic GI nematode from the European field mouse, conspecific with the OTU H. polygyrus (bakeri), the widely used laboratory model which was isolated on a single occasion from an American deer mouse? Durette-Desset et al. (1972) supported this notion, and proposed 2 testable hypotheses: (1) that $H$. p. bakeri and H. p. polygyrus are sister terminal clades and therefore each other's closest relative; and (2) that the two taxa have diverged in recent historical times since the imposition of allopatry when $H$. $p$. bakeri was introduced, in house mice, to the New World as a result of human activity during, or shortly after, the conquest some 500 years before present (BP). According to this model the morphological and biological differences between $H$. p. bakeri and $H$. p . polygyrus relate to the genetic bottlenecking experienced on introduction to the New World and subsequently when taken into culture. The implications of these hypotheses are considerable in that, if supported, the OTUs would be sufficiently closely related (subspecies or closer) that findings from one could be extrapolated to the other, allowing a synthesis of physiological, immunological and ecological observations of GI nematode biology. However, testing these hypotheses is not straightforward. Heligmosomatids lack informative morphological characters and identification relies heavily on host identity (Durette-Desset, 1971; Asakawa, 1988). Morphological distinction depends on the precise arrangement and number of cuticular ridges (arêtes), which comprise the synlophe (Durette-Desset, 1971; Durette-Desset et al. 1972) and asymmetry of the caudal bursa and arrangement of rays, especially the dorsal rays, complement the identification (Genov and Yanchev, 1981). The synlophe characters in particular are correlated with worm body size and possibly host identity (Durette-Desset et al. 1972) and the range of variation within, and between the taxa is impossible to evaluate, as all cultures of the laboratory model are derived from a single isolate.

In this study, we used a molecular approach to examine the relationship between the two OTUs of $H$. polygyrus, by analysing the internal transcribed spacers (ITS) of the ribosomal DNA (rDNA) and the mitochondrial cytochrome c oxidase I (COI) gene of $H$. polygyrus from the wood mouse $A$. sylvaticus and comparing it with a laboratory strain of this worm maintained in laboratory mice. Additional material of related Heligmosomoides and Heligmosomum species was also included. This dual molecular approach combines the advantages, and overcomes some of the disadvantages, of focussing on just nuclear or mitochondrial DNA (see Hillis and Dixon, 1991; Mayer and Soltis, 1999; Avise, 2000). It does not, however, clarify precise species boundaries without a statistically defined framework (Sites and Marshall, 2004). We have therefore assessed pairwise differences between populations and used analysis of molecular variance (AMOVA, Excoffier et al. 1992), to test the hypotheses formulated by Durette-Desset et al. (1972) concerning the origin of $H$. polygyrus bakeri for congruence with variation in the molecular data.

\section{MATERIALS AND METHODS}

\section{Parasite collection and fixation}

Specimens of Heligmosomoides polygyrus maintained in the laboratory mouse, Mus musculus, in Nottingham since 1976 and isolates from the wood mouse Apodemus sylvaticus from Britain (6 sites), the Channel Isles and Portugal were compared with samples of $H$. glareoli and Heligmosomum mixtum from Poland (see Table 1). Rodents caught in Sherman traps were killed with an overdose of ether. The gut from each host was removed onto a fine mesh gauze suspended in Hanks' balanced salt solution and placed at $37^{\circ} \mathrm{C}$ for up to $1 \mathrm{~h}$ to allow worms to migrate into the saline. Individual nematodes were collected from the saline or in some cases removed directly from the intestinal mucosa and preserved in $90 \%$ ethanol. Nematodes were stored at $-20{ }^{\circ} \mathrm{C}$ prior to DNA extraction and sequencing.

\section{Sequencing of the ITS and COI}

DNA was isolated from individual worms using a QIAamp ${ }^{\circledR}$ DNA Minikit (Qiagen) and eluted into $200 \mu \mathrm{l}$ of AE buffer provided with the kit. Initially, for rDNA amplification, primers NCOF (5' TTGAACCGGGTAAAGTCGT 3'; $3^{\prime}$ end of $18 \mathrm{~S}$ ) from Anderson (1995), and NC1F (5' ACGTCTGGTCAGGGTTGTT $3^{\prime} ; 3^{\prime}$ end of $5 \cdot 8 \mathrm{~S}$ ) and $\mathrm{NC} 2 \mathrm{R}$ (5' TTAGTTTCTTTTCCTCCGCT 3'; 5' end of 28S) from Chilton et al. (1997) were used in $10 \mu \mathrm{l}$ PCRs. These contained $c a$. $10 \mathrm{ng}$ DNA, $50 \mathrm{~mm} \mathrm{KCl,}$ $10 \mathrm{~mm}$ Tris- $\mathrm{HCl}, 1.5 \mathrm{~mm} \mathrm{MgCl}_{2}, 0.2 \mathrm{~mm}$ of each dNTP, $0.3 \mathrm{~mm}$ of each primer and $1 \mathrm{U}$ Taq DNA polymerase (Invitrogen). The standard thermal profiles and cycle times used were $94{ }^{\circ} \mathrm{C}$ for $3 \mathrm{~min}$ followed by $94{ }^{\circ} \mathrm{C}$ for $30 \mathrm{~s}, 50{ }^{\circ} \mathrm{C}$ for $45 \mathrm{~s}, 72{ }^{\circ} \mathrm{C}$ for $1 \mathrm{~min}$ ( 35 cycles), and $72^{\circ} \mathrm{C}$ for $10 \mathrm{~min}$ in a $\mathrm{PE}$ Applied Biosystems Gene Amp PCR System 9700 thermal cycler. From partial sequences of $H$. $p$. bakeri, new primers were designed from the $5^{\prime}$ end of the $5 \cdot 8 \mathrm{~S}$ gene, $\mathrm{NC} 1 \mathrm{Fb}\left(5^{\prime}\right.$ ACGTCTGGTTCAGGGTTGT 3') and NC1R (5' ACAACCCTGAACCAGACGTG 3'). The annealing temperature of the PCRs utilizing these new primers was increased to $60-67{ }^{\circ} \mathrm{C}$ (depending on taxa). 
Table 1. Host locality and collection dates of heligmosomatids analysed

\begin{tabular}{|c|c|c|c|c|c|}
\hline Parasite taxon & Locality & Origin/Collected & Host $(n)$ & $\begin{array}{l}\text { Adult parasites sequenced } \\
(n) \text { rDNA, ITS and } 5 \cdot 8 \mathrm{~S}\end{array}$ & mtDNA, COI \\
\hline \multicolumn{6}{|c|}{ Previous study (see Sukhdeo et al. 1997) } \\
\hline $\begin{array}{l}\text { Heligmosomoides polygyrus } \\
\text { bakeri }\end{array}$ & USA & Laboratory infection & Mus musculus & - & $649 \mathrm{bp}$ \\
\hline \multicolumn{6}{|c|}{ Previous study (see Audebert et al. 2005) } \\
\hline $\begin{array}{l}\text { Heligmosomoides polygyrus } \\
\text { bakeri }\end{array}$ & USA & $\begin{array}{l}\text { Laboratory infection } \\
\text { (INRA Tours) }\end{array}$ & Mus musculus & ITS1, ITS2 \& $5 \cdot 8 \mathrm{~S}$ & - \\
\hline \multicolumn{6}{|l|}{ Current study } \\
\hline $\begin{array}{l}\text { Heligmosomoides polygyrus } \\
\text { bakeri }\end{array}$ & USA & $\begin{array}{l}\text { Laboratory infection } \\
\text { (Nottingham, U.K.) } \\
\text { March 1997-July } 2003\end{array}$ & Mus musculus & 3 (ITS1, ITS2 and 5·8S) & $2(618 \mathrm{bp})$ \\
\hline H. p. polygyrus & Aqualate Estate, Shropshire, UK & March 2000 & \multirow{2}{*}{$\begin{array}{l}\text { Apodemus sylvaticus } \\
\text {, }\end{array}$} & 3 (ITS1, ITS2 and 5·8S) & $2(567 \mathrm{bp})$ \\
\hline & Skegness, UK & March 2000 & & $5(\mathrm{ITS} 1, \mathrm{ITS} 2$ and $5 \cdot 8 \mathrm{~S})$ & $3(598$ bp) \\
\hline , & Dungeness, Kent, UK & June 2000 &, & 1 (ITS2) & 0 \\
\hline ", & Aberdeen, UK & Feb. 1997 & " & 1 (ITS1, ITS2 and 5·8S) & $2(532 \mathrm{bp})$ \\
\hline ” & Belfast, UK & May 2000 & "’ & 1 (ITS2) & $2(532 \mathrm{bp})$ \\
\hline ", & Newborough Warren, Anglesey, UK & March 2003 & ", & 0 (sequencing repeatedly failed) & $2(613 \mathrm{bp})$ \\
\hline " & Guernsey, Channel Isles & March 2003 & " & 0 (sequencing repeatedly failed) & $2(613 \mathrm{bp})$ \\
\hline " & Sobreda, Portugal & April 1991 & " & 1 (ITS2) & 0 \\
\hline H. glareoli & Lake Śniardwy, Mikolajki, Poland & Aug. 2002 & Clethrionomys glareolus & 1 (ITS2 and $5 \cdot 8 \mathrm{~S})$ & $1(567 \mathrm{bp})$ \\
\hline Heligmosoтит mixtum & Lake Śniardwy, Mikolajki, Poland & Aug. 2002 & & $3(\mathrm{ITS} 1, \mathrm{ITS} 2$ and $5 \cdot 8 \mathrm{~S})$ & $1(567 \mathrm{bp})$ \\
\hline
\end{tabular}


The original primers for amplifying the mtDNA cytochrome $\mathrm{c}$ oxidase subunit I gene (COI) were designed for Gyrodactylus turnbulli (Cable and Harris, unpublished observations); P9 (5' ('TG)(AT) T(GA) AT(TC)GG(TG)GGTTTTGGTAA 3') and P10 (5' TCATACCAAAAGCAGGTA 3'). PCRs commenced at $94{ }^{\circ} \mathrm{C}$ for $3 \mathrm{~min}$, followed by $94{ }^{\circ} \mathrm{C}$ for $30 \mathrm{~s}, 50{ }^{\circ} \mathrm{C}$ for $30 \mathrm{~s}, 72{ }^{\circ} \mathrm{C}$ for $2 \mathrm{~min}(35$ cycles), and $72^{\circ} \mathrm{C}$ for $10 \mathrm{~min}$ in a Stratagene ${ }^{\mathbb{R}}$ Robocycler Gradient 96. Subsequently, primers LCO (5' GGTCAACAAATCATAAAGATATTGG 3') and HCO (5' TAAACTTCAGGGTGACCAAAAAATCA 3') (Folmer et al. 1994) were shown to yield more consistent PCR products in $25 \mu \mathrm{l}$ PCRs with $0.1 \mathrm{~mm}$ of each primer, run at $95{ }^{\circ} \mathrm{C}$ for $1 \mathrm{~min}$, followed by $95{ }^{\circ} \mathrm{C}$ for $1 \mathrm{~min}, 50{ }^{\circ} \mathrm{C}$ for $1 \mathrm{~min}, 72{ }^{\circ} \mathrm{C}$ for $1.5 \mathrm{~min}$ ( 35 cycles), and $72{ }^{\circ} \mathrm{C}$ for $7 \mathrm{~min}$ in a $\mathrm{PE}$ 9700. A negative control sample (without DNA) was included with each ITS and COI amplification.

PCR products were purified using a GeneClean III kit (Anachem) and sequenced using an ABI PRISM $^{\text {TM }}$ Dye Terminator Cycle Sequencing Ready Reaction Kit, following the manufacturer's guidelines, and run on an ABI 377 automatic sequencer. All samples included in the final analysis were sequenced at least twice using both forward and reverse primers. Sequences were aligned using SEquencher V.3.1.2 (Gene Codes Corporation, Inc.) and verified by eye. Sequences representing the $5 \cdot 8 \mathrm{~S}$, $18 \mathrm{~S}$ and $28 \mathrm{~S}$ genes were determined by BLAST searches. The alignment of COI sequences remained in frame for amino acid translation when compared to the sequence from Heligmosomoides polygyrus determined by Sukhdeo et al. (1997). All ITS and COI sequences were trimmed leaving the longest common alignment for all specimens examined. Alternative ITS alignments (322 bp, with nematode outgroups, and $262 \mathrm{bp}$ and $265 \mathrm{bp}$ without these outgroups) were also analysed, but as the resulting tree topologies were almost identical, just the data from a $321 \mathrm{bp}$ alignment is referred to below. Nucleotide sequences for ITS and COI were deposited in GenBank (Accession nos. DQ408618 to DQ408626 and DQ408627 to DQ408635).

\section{Phylogenetic analysis}

Parsimony, Distance (neighbour-joining, NJ, and minimum evolution, ME) and Maximum Likelihood (ML) analyses were performed in PAUP* 4.0b 10 PPC (Swofford, 2003) separately on the ITS2 (321 bp) and COI (439 bp) data sets. ITS sequences were included from the related nematodes, Ohbayashinema erbaevei (GenBank AY332647 and AY333381, see Audebert et al. 2005) and Trichostrongylus colubriformis (GenBank S69220, see Hoste et al. 1993). The models of DNA evolution that best fitted the data based on log likelihood scores was calculated using Modeltest 3.06 (Posada and
Crandall, 1998), following the Akaike Information Criterion recommended by Posada and Buckley (2004). ML and ME analyses were performed using the parameter estimates under the best-fit models as $\mathrm{K} 81 \mathrm{uf}+\mathrm{G}$ and $\mathrm{GTR}+\mathrm{I}+\mathrm{G}$, respectively, for the alignments of ITS2 and COI sequences. For each analysis, 1000 replicates of the random addition heuristic search option were performed with TBR branch swapping.

\section{Analysis of COI genetic diversity and differentiation}

Population genetic structure was determined using minimum spanning network analysis for COI in the program ARLEQUIN 2.000 (Schneider et al. 2000). This program was also employed to calculate pairwise genetic distances for each haplotype, which were then plotted in EXCEL. Finally, ARLEQUiN was used to perform an analysis of molecular variance (AMOva; Excoffier et al. 1992) to first test whether all clusters were sufficiently distinct to reject the hypothesis that they belong to a single evolutionary group. Subsequent hypotheses, that the individually identified populations are geographically, biologically and ecologically interchangeable, were also tested by amova. Specifically, 4 hypotheses about the grouping of COI haplotypes (Table 2) were tested. (1) There are no significant differences between Eurasian heligmosomatid isolates (H. p. polygyrus, $H$. mixtum and $H$. glareoli) and North American isolates (H. p. bakeri). (2) There are no significant differences between heligmosomatids grouped according to host infected (i.e. the vole infecting $H$. glareoli and H. mixtum vs. the wood mouse infecting H.p.polygyrus vs. the laboratory mouse infecting H.p. bakeri). (3) There are no significant differences between heligmosomatids grouped according to conventionally recognized morphological taxonomy (i.e. H. glareoli vs. H. mixtum vs. H. polygyrus). (4) There are no significant differences between heligmosomatids grouped according to ribosomal DNA identity (i.e. H. glareoli vs. H. mixtum vs. H. $p$. polygyrus vs. H. p. bakeri). The significance of variation was assessed by 16000 permutation tests (Excoffier et al. 1992).

\section{RESULTS}

The amplified rDNA fragment ( 3 'end of $18 \mathrm{~S}$, ITS1, $5 \cdot 8 \mathrm{~S}$, ITS2 and 5 'end of $28 \mathrm{~S}$ ) varied from $987 \mathrm{bp}$ for Heligmosomum mixtum to $1040 \mathrm{bp}$ for the laboratory isolate of Heligmosomoides polygyrus. Direct sequencing of ITS was problematic with only partial sequences obtained for some samples (Table 1), perhaps reflecting high levels of intra-individual variation in isolates from wood mice. Individual worms contained polymorphisms at 7 positions in the $308 \mathrm{bp}$ ITS2 sequence, but there was little consistent variation between sites, and for example only a single base distinguished the individual 
Table 2. Analysis of variance among heligmosomatid populations based on $439 \mathrm{bp}$ of the mitochondrial cytochrome c oxidase subunit I gene

(The percentage of total variance (derived from $\Phi_{\mathrm{CT}}$ ) that is explained by the grouping is indicated as well as the significance levels associated with rejection of $\mathrm{H}_{0}$.)

\begin{tabular}{|c|c|c|c|}
\hline Hypothesis & $\begin{array}{l}\text { Percentage } \\
\text { among } \\
\text { groups }\end{array}$ & $\mathrm{P}$ & $\mathrm{H}_{0}$ \\
\hline $\begin{array}{l}\text { Geographical origin } \\
{[\text { America][Eurasia] }}\end{array}$ & $53.9 \%$ & $0 \cdot 110$ & Accept \\
\hline $\begin{array}{l}\text { Host identity [Clethrionomys }] \\
{[\text { Apodemus }][\mathrm{Mus}]}\end{array}$ & $50 \cdot 5 \%$ & $0 \cdot 015$ & Reject \\
\hline $\begin{array}{l}\text { Morphology [Heligmosomum }] \\
{[\text { H.glareoli }][\text { H.polygyrus }]}\end{array}$ & $28 \%$ & $0 \cdot 291$ & Accept \\
\hline $\begin{array}{l}\text { ITS sequence }[\text { Heligmosomum }] \\
{[\text { H.glareoli }][\text { H.p.polygyrus }][\text { H.p. bakeri }]}\end{array}$ & $89 \cdot 7 \%$ & $0 \cdot 017$ & Reject \\
\hline
\end{tabular}

Aberdeen worm sequenced from all other worms from wood mice. The Nottingham laboratory strain was compared with the French INRA-Tours strain (Audebert et al. 2005) and the ITS2 of the two strains was identical. Overall, the laboratory strains differed from a consensus sequence for the wood mouse strain by $3 \cdot 3 \%$.

Part of the variation noted within $H$. p. polygyrus was due to length variation in a short microsatellite $\left(\mathrm{GT}_{3-4}\right)$ sequence within ITS2. Most worms exhibited a $(\mathrm{GT})_{3}$ repeat, but the Aberdeen worm, and 3 of 5 worms from Skegness sequenced contained a $(\mathrm{GT})_{4}$ unit. Intra-individual ITS variation was also noted within $H$. glareoli $(3 / 559 \mathrm{bp})$ but not amongst $H$. mixtum individuals. The degree of intra-specific variation in the ITS was not explored further as the level of discrimination revealed by mtDNA COI sequencing (see below) was more informative in addressing the aims of the current study.

Almost all indels within the ITS region were due to the inclusion of $H$. mixtum and the outgroups within the data set. Comparison of 5 samples for which there were complete ITS1 and ITS2 sequences revealed greatest variation in ITS2 $(22.9 \%$ including indels, $15.4 \%$ excluding indels), while for ITS1 the corresponding figures were $18 \cdot 2 \%$ and $7 \cdot 8 \%$. The $5 \cdot 8 \mathrm{~S}$ sequence $(152 \mathrm{bp})$ was identical for all worms and was therefore excluded from the analysis, as was the microsatellite repeat unit in the ITS2. Distance and parsimony trees based on ITS2 show complete congruence with all likelihood trees (Fig. 1), with $H$. p. polygyrus being more similar to $H$. p. bakeri than to $H$. glareoli. Support for the terminal clades $H . p$. polygyrus and $H$. p. bakeri was strong (over $80 \%$ in all trees). Although in a separate genus, Ohbayashinema erbaevei appears to cluster with Heligmosomoides glareoli (another voleinfecting species), suggesting that it is not sufficiently distantly related to be an effective outgroup. For this reason, Trichostrongylus colubriformis, belonging to a different family of nematodes, proved the most suitable outgroup.

Sequence data for 532-618 bp for the COI fragment were obtained, with product length being dependent upon the primer set used. Comparison of $599 \mathrm{bp}$ of COI sequence between the Nottingham laboratory isolate of $H$. polygyrus bakeri (USA) and that maintained in Montreal by Sukhdeo et al. (1997; Accession no. U57034), revealed a single, synonymous base-pair substitution ( $\mathrm{T}$ to $\mathrm{C}$ ) ; a $99 \cdot 8 \%$ similarity between the two laboratory isolates. However, a $439 \mathrm{bp}$ fragment common to all isolates (from laboratory mice and Eurasian wood mice) contained 83 variable and 51 informative sites, with distinct haplotypes from each wood mouse population. Overall, the laboratory isolates differed by $8 \%(35 / 439 \mathrm{bp})$ from the $5 \mathrm{UK}$ wood mouse isolates of $H$. polygyrus. Variation among these mouse isolates (excluding Guernsey) was less than 1.6\%. This variation included single transitions between the Skegness, Aberdeen and Belfast isolates, and 2 transitions between the Staffordshire and Anglesey isolates. MtCOI polymorphisms were not shared between sites, and within sites the variation was consistent between individuals, except at Skegness, where 3 worms exhibited an $\mathrm{A} / \mathrm{G}$ polymorphism within the population sample. The Guernsey isolate varied by more than $8 \%$ from both other wood mouse isolates and from the laboratory strains of Heligmosomoides.

Phylogenetic trees constructed using COI parsimony and distance based trees gave an identical topology, with UK wood mouse isolates forming a single clade with $H$. glareoli, separated from the two H. p. bakeri isolates. Using Maximum Likelihood, the $H$. p. bakeri clade was not distinguishable from the H. p. polygyrus/H. glareoli clade, but bootstrap support for all branches was low. In all these analyses, the Guernsey isolate of $H$. p. polygyrus and $H$. mixtum provided sister groups for the 


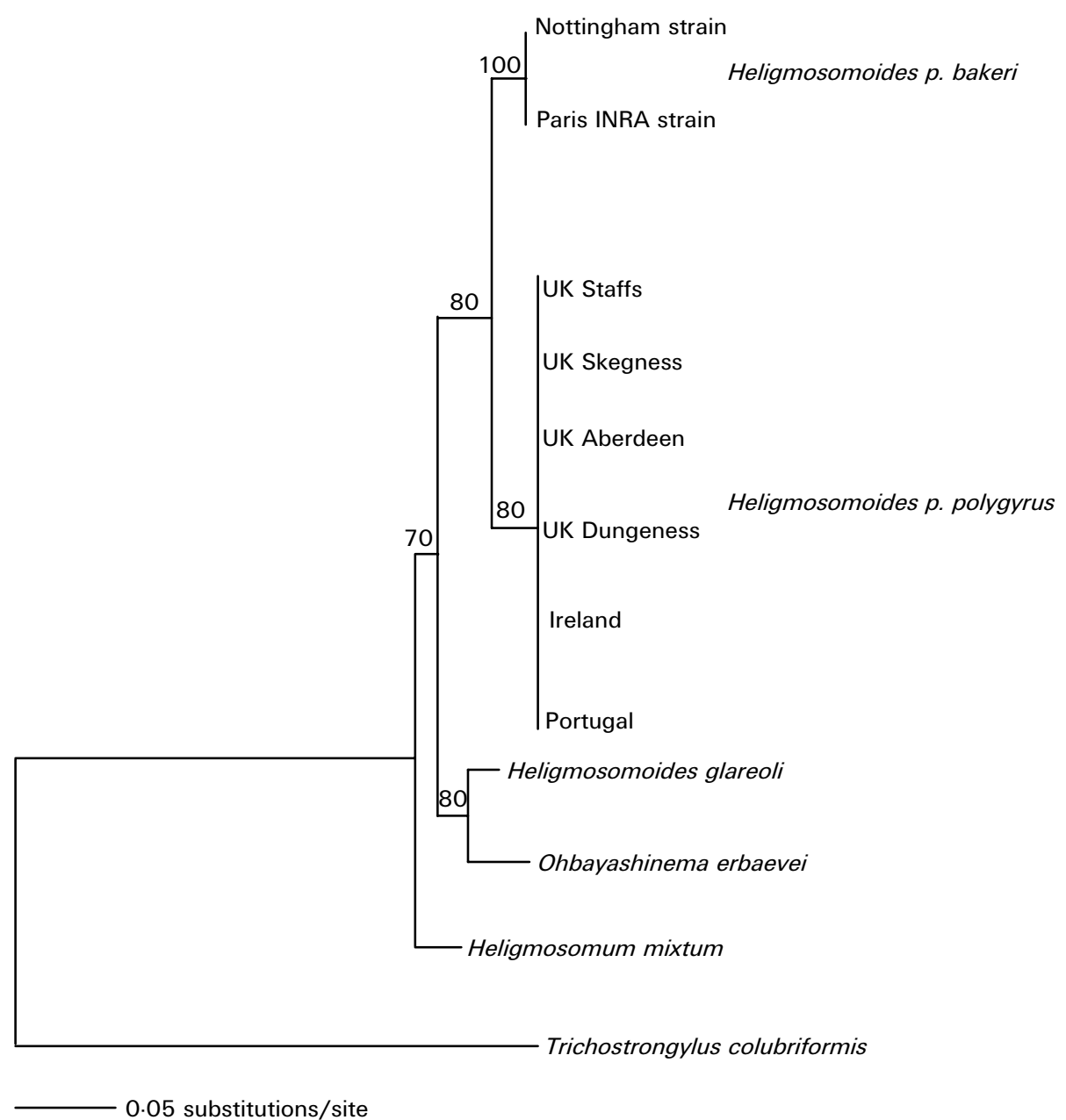

Fig. 1. Maximum Likelihood analysis of heligmosomids based on Internal Transcribed Spacer 2 sequence data using likelihood parameters base frequencies $=0 \cdot 2609,0 \cdot 1783,0 \cdot 2216,0 \cdot 3392$; rate matrix $(1 \cdot 0000,8 \cdot 8865,2 \cdot 9368,2 \cdot 9368$, $8 \cdot 8865,1 \cdot 0000)$; gamma distribution shape $=1 \cdot 1062$; proportion of variable sites $=0 \cdot 4267$.

H. p. polygyrus/H. glareoli/H. p. bakeri clade (data not shown). A minimum spanning network, however, revealed 4 distinct clusters of COI haplotypes, separated from each other by 39 substitutions (Fig. 2). The UK mainland wood mouse isolates of H. p. polygyrus formed a central cluster, closely associated with the Polish isolate of $H$. glareoli (separated by 9 substitutions). The Polish H. mixtum, the Guernsey wood mouse isolate and the laboratory cultures of $H$. p. polygyrus then formed equidistantly spaced outliers (Fig. 2). All analyses indicate that the variation in $\mathrm{mtCOI}$ sequence is explained by morphology (Heligmosomum vs. Heligmosomoides) and host genus (Clethrionomys vs. Apodemus), or with geographical origin (North America or Guernsey).

\section{Population variability: partitioning according to} hypotheses of species relationships

The structuring in COI haplotypes relative to conventional taxonomic groupings is shown in Fig. 3, based on pairwise genetic distances between each pair of haplotypes. Intra-OTU comparisons
(H.p. bakeri or H. p. polygyrus) cluster with a pairwise genetic distance of 1-6, whereas inter-OTU genetic distances are generally greater than this. The smallest inter-OTU distances are those between $H$. p. polygyrus and $H$. glareoli, which cluster at 9 and 10 (see Fig. 3). Genetic distances between $H$. p. bakeri and the H. p. polygyrus isolates, and between all OTUs and $H$. mixtum, fall in the range 39-55. The only exceptions to this pattern are pairwise distances involving $H$. p. polygyrus from Guernsey, which cluster at a distance of ca. 40 units from other H. p. polygyrus isolates (Fig. 3).

AMOVA (Excoffier et al. 1992) used to test 4 explicit hypotheses about the structuring of mitochondrial COI haplotypes (Table 2) indicated the following. (1) There was no significant partitioning of the mtCOI variance between Eurasian heligmosomatid isolates (H. p. polygyrus, H. mixtum and $H$. glareoli) and the North American H. p. bakeri $\left(\mathrm{H}_{0}\right.$ accepted, $\left.P>0 \cdot 11\right)$. (2) There is, however, significant partitioning of haplotype variance between heligmosomatids grouped according to host infected $\left(\mathrm{H}_{0}\right.$ rejected, $\left.\mathrm{P}<0 \cdot 05\right)$. (3) There was no significant 


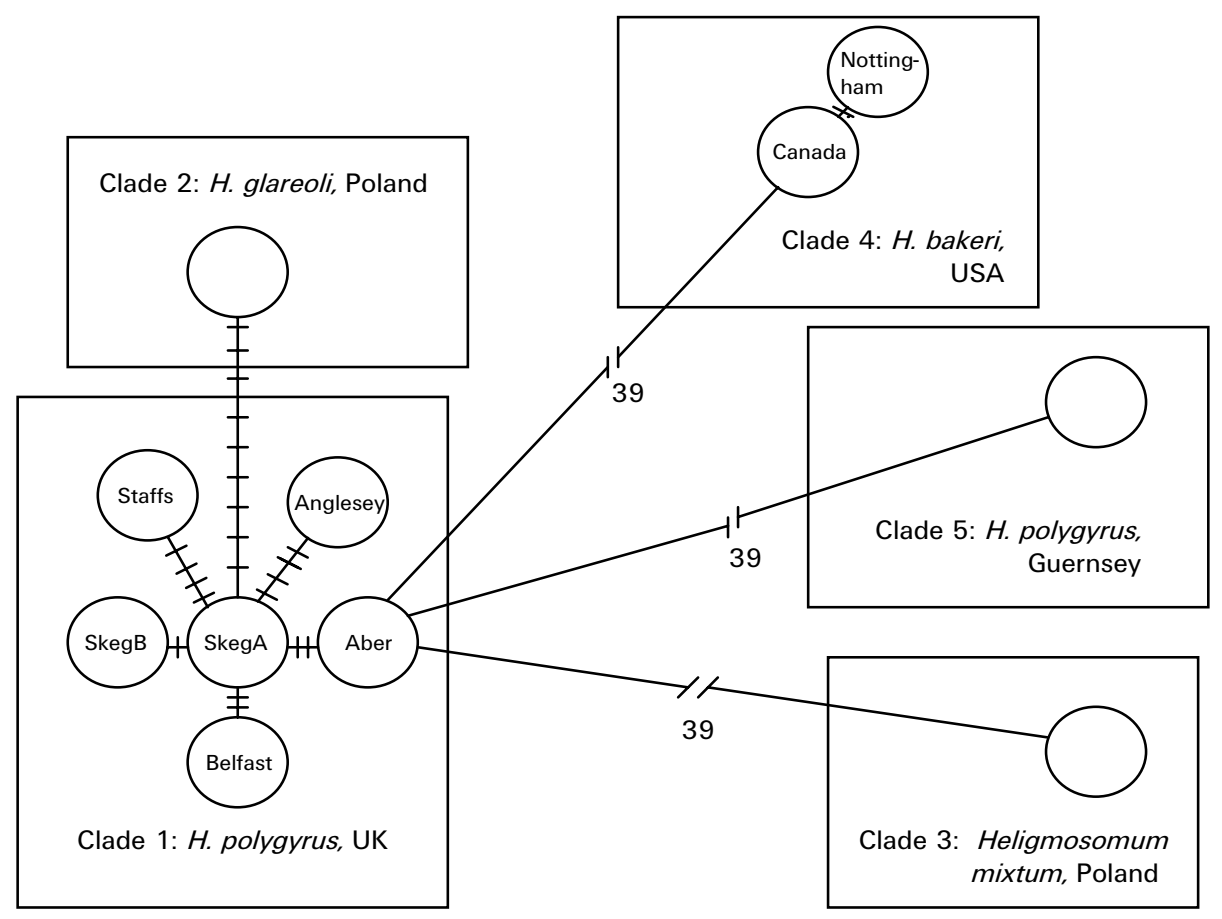

Fig. 2. Minimum spanning network for mitochondrial cytochrome c oxidase subunit I haplotypes of Heligmosomoides and Heligmosomum taxa. Heligmosomum mixtum, Heligmosomoides polygyrus bakeri and the Guernsey isolate of $H$. p. polygyrus are separated by 39 substitutions from the central cluster of mainland UK, H. p. polygyrus haplotypes (Staffordshire, Anglesey, Aberdeen, Belfast and 2 individuals from Skegness, A and B) and H. glareoli. Elsewhere base pair substitutions are represented by short black lines at right angles to the lines connecting haplotypes, see text for details.

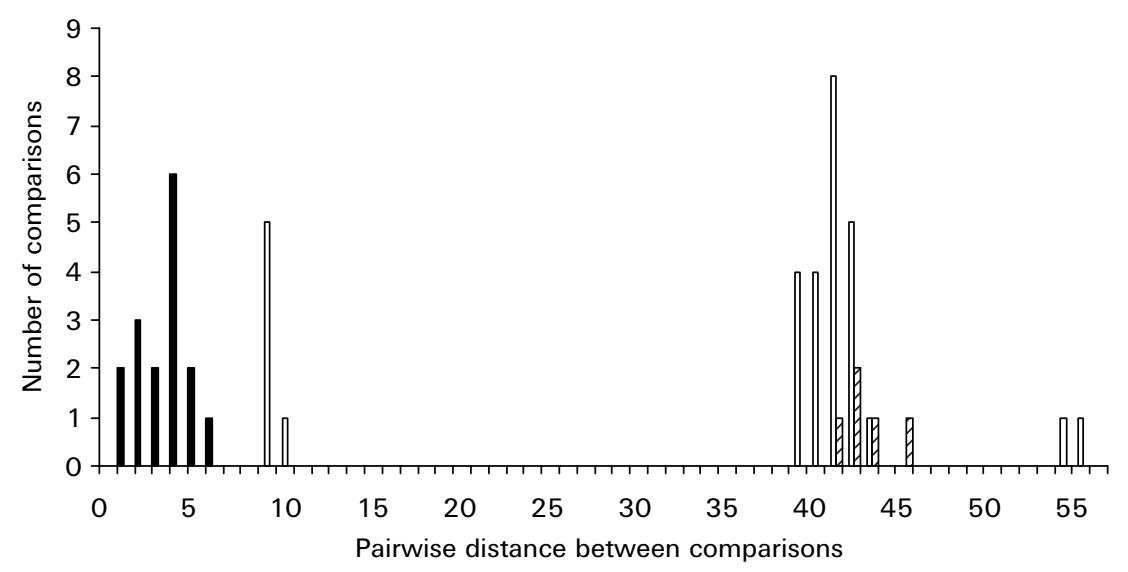

Fig. 3. Pairwise genetic differences of mitochondrial cytochrome c oxidase subunit I sequences among heligmosomid Operational Taxonomic Units (see Table 1 for details of specimens). Pairwise intra-specific comparisons (among both UK mainland isolates of Heligmosomoides polygyrus polygyrus and among the 2 laboratory isolates of H.p. bakeri) indicated with closed bars (with the exception of those involving H.p.polygyrus samples from Guernsey being represented by shaded bars), and inter-specific comparisons (H.p.polygyrus vs. H. glareoli vs. H. p. bakeri) with open bars.

partitioning in haplotype variance between heligmosomatids grouped according to conventionally recognized morphological groupings, which treat H. p. polygyrus and H. p. bakeri as a single taxon $\left(\mathrm{H}_{0}\right.$ accepted, $\left.P>0 \cdot 29\right)$. (4) There was significant partitioning of haplotype variance between heligmosomatids grouped according to ribosomal DNA identity, which separates $H$. p. polygyrus and $H$. p. bakeri $\left(\mathrm{H}_{0}\right.$ rejected, $\left.P<0 \cdot 05\right)$.

Structuring in COI haplotypes was therefore significantly correlated with host identity (voles $v s$. wood mice $v s$. house mice) and with nematode OTU as established by ribosomal ITS sequence identity (H. mixtum vs. H. glareoli vs. H. polygyrus polygyrus 
vs. H. polygyrus bakeri). It was not correlated with geographical origin or with conventional taxonomic assignation (H. mixtum vs. H. glareoli vs. H. polygyrus).

\section{DISCUSSION}

The present findings suggest that Heligmosomoides polygyrus polygyrus and $H$. p. bakeri are terminal sister clades. Analysis of ribosomal ITS2 sequences showed that these taxa cluster together, distinct from a second grouping including $H$. glareoli, Heligmosomum mixtum and the vole heligmosomatid Ohbayashinema erbaevei. Tree topology was consistent in linking all isolates of $H$. p. polygyrus with laboratory isolates of $H$. p. bakeri, but the relationship between the two OTUs was quite distant. The separate terminal clades have significant bootstrap support, and the ITS2 sequences of the two taxa differed by $3 \%$. With the more rapidly evolving COI sequences, a cluster of terminal clades corresponding to the UK isolates of $H$. p. polygyrus were clearly separated by 39 mutational steps from the laboratory isolates.

Species status in nematodes is often simply inferred by molecular distance between isolates. Thus, Blouin (2002) stressed the value of mitochondrial loci in highlighting large molecular distances between nematode species. This assumes a greater interspecific genetic distance between taxa than the intraspecific distances, a condition that appears to hold in the present case, in all pairwise comparisons of genetic distance except those including the Guernsey isolate of $H$. p. polygyrus. The cryptic Haemonchus placei, for example, was differentiated by $15 \%$ sequence variation from $H$. contortus at the mitochondrial ND4 locus (Blouin et al. 1997), while Zhu et al. (2002) recorded differences in ITS sequence of approximately $2 \%$ amongst the cryptic nematode species of the Pseudoterranova decipiens complex. In both cases, as in the $H$. polygyrus complex, species status is based on little more than small morphological differences, differences in host identity and sequence variation. This assumption that molecular differences match differences in specific status also underlies the work of Eyualem and Blaxter (2003), who showed that ribosomal DNA sequences matched closely with species of Panagrolaimus as indicated by cross-breeding experiments but not by morphology. Nevertheless, simple sequence differences are not by themselves sufficient to establish species identity. Adams (1998) in particular criticized the application of typological and biological species concepts to nematodes, recommending instead phylogeny reconstruction based on the Phylogenetic Species Concept. Blouin (2002) reflected this, noting that molecular distances should be only the first step in identifying cryptic nematode species, and that full recognition of their status requires considerable further work. ITS sequences, which change by concerted evolution, are generally homogenous within a species (Gasser et al. 1996), although exceptions within the nematodes are known. Hypodontus macropi, from kangaroos, for example, showed up to $5 \%$ intra-specific variation at ITS2, due primarily to slippage at dinucleotide repeats (Gasser et al. 2001), while the plant parasite Meloidogyne had a wide diversity of ITS sequence clusters, related to its evolutionary history of divergence and interspecific hybridization (Hugall et al. 1999). Thus, our analysis, with sequence differences of this magnitude in both ITS and COI between the two OTUs of $H$. polygyrus, suggests, but does not confirm, their status as independent species.

The AMOVA (Excoffier et al. 1992) more rigorously establishes whether variation in molecular sequences is partitioned along discontinuities observed with other approaches, reflecting differences between valid species following independent evolutionary trajectories. In the present case, it is clear from ITS2 and COI datasets that H. p. polygyrus and $H$. p. bakeri represent significantly different, if closely related, clades. For these clades to be elevated to species status, there should be no evidence of recent genetic interchange between them. If a $H$. p. bakeri COI haplotype or ITS sequence was recovered from a nematode from a European wood mouse, for example, support for the specific status of the two forms would be greatly weakened. In fact, there is congruence between molecular sequences and the biological taxa they represent; the group of COI haplotypes collected from European wood mouse parasites clustered closely together, separated by 39 mutational steps from the two COI isolates from the laboratory isolates. There was no significant association between different haplotypes and geographical origin, but there was a significant relationship between haplotypes and host identity (wood mouse vs. laboratory mouse vs. voles), and between haplotypes and the OTUs recognized on the basis of rDNA sequences (Heligmosomum mixtum vs. Heligmosomoides glareoli vs. H. polygyrus polygyrus vs. H. p. bakeri). These associations suggest strongly that $H$.p. bakeri and H.p.polygyrus, with their differences in ITS and COI sequences, host identity, ecological preference and geographical origin do indeed represent distinct species.

Previous workers had suspected that the difference between laboratory isolates of $H$. polygyrus and those from wood mice might be considerable (DuretteDesset et al. 1972; Durette-Desset, 1985 ; Asakawa, 1988). In particular, Quinnell et al. (1991) reported that $H$. p. polygyrus from wild wood mice was unable to mature in laboratory mice, since very few larvae survived the tissue phase of infection. Some H. $p$. bakeri completed their development to the adult 
stage in wood mice, but most were rejected within 2-3 weeks unless the animals were treated with the immunosuppressive drug cortisone. Also, Abu-Madi et al. (1994) found differences between the two OTUs in protein synthesis and Abu-Madi et al. $(2000 b)$ showed, using RFLP, that the taxa could be distinguished by 8 endonuclease digestions of the ITS region, a finding consistent with the $3 \%$ sequence divergence at this locus.

The question remains as to whether the two taxa could be recently diverged sister species. Peromyscus maniculatus is not thought to be the natural host for the laboratory form (Forrester and Nielson, 1973), and the earliest records of the worm in America were from the mouse Mus musculus (e.g., Spurlock, 1943). In Europe an additional subspecies, H.p. corsicus was identified from the house mouse in Corsica (DuretteDesset et al. 1972), raising the possibility that $H$. polygyrus is a Holarctic taxon, spread to the New World with commensal house mice, from which it has spread to infect Nearctic rodents, undergoing subspeciation as a result (Durette-Desset, 1985). According to this hypothesis, $H$. polygyrus spread first into Mus and Reithrodonontomys, then into Phenacomys, both subspecific radiations occurring in the 300 years since mice were first introduced into the New World (Durette-Desset, 1985). However, it would be most surprising if $H$. p. bakeri had undergone sequence divergence of $3 \%$ in the ITS and $8 \%$ in the COI since putative introduction to the New World via trans-Atlantic shipping. Nieberding et al. $(2004 a)$ estimated a divergence rate at the mitochondrial cyt $b$ gene of approximately $2.5 \%$ per million years, suggesting that the split between $H$. p. polygyrus and $H$. p. bakeri is at least 3 million years old. Based on our present findings, the hypothesis of Durette-Desset (1985) that H.p. bakeri reached the Nearctic with imported house mice from Europe cannot be rejected. However, if this did occur, the extent of sequence divergence indicates that this parasite was already distinct from H. p. polygyrus before introduction. Alternatively, Asakawa (1988) has suggested that the polygyrus strain spread to North America from the Palaearctic via Asia in murid hosts, subspeciating in the process. Based on morphology, H. polygyrus bakeri has been recorded in Japanese Mus musculus while an apparently closely related species, H. neopolygyrus, parasitizes Apodemus peninsulae (see Asakawa, 1991; Asakawa and Ohbayashi, 1986). Since other species of the genus Heligmosomoides probably spread to North America via the Bering Strait in microtids, some of which may have secondarily adapted to nonmicrotid hosts (Asakawa, 1988), H. p. bakeri is more likely to be a member of these lineages, rather than a close relative of the other European $H$. polygyrus subspecies. Asakawa's (1988) hypothesis is also more consistent with the degree of divergence in ITS and COI sequences between the two nematodes, and suggests that the sister taxa of $H$. p. bakeri are probably to be found in North American or Eastern Eurasian rodents.

Although AMOVA supports the specific identity of the laboratory isolate, it raises substantial doubts about the status of $H$. p. polygyrus. The single COI haplotype from $H$. glareoli is only 9 mutational substitutions from the cluster of $H$. p. polygyrus haplotypes, while a haplotype from wood mouse parasites from Guernsey is almost 40 substitutions distant from mainland UK forms. Nieberding et al. $(2004 b)$ in their survey of mitochondrial $c y t b$ variation in the wood mouse OTU, also recorded distances between haplotype clusters in excess of 30 steps. They interpreted this as evidence of deep and ancient structuring, a consequence of evolution in separate glacial refugia, dated to 1-2 million years ago (MYA) (Nieberding et al. 2004b). The lack of correlation between the loci sequenced (cyt $b$ by Nieberding et al. 2004a,b; COI and ITS in the present study) makes direct comparison difficult. However, Nieberding et al. (2004b) included Irish specimens in their work, and comparison with our Belfast specimens suggests that all UK mainland populations (excluding the Guernsey isolate) would cluster in the Danish/Irish clade 5 of Nieberding et al. (2004b). This perhaps is not surprising, as it is generally accepted (Berry, 1985) that Apodemus sylvaticus reached Ireland by human intervention, probably in the medieval period, either from mainland Britain or from one of the Scandinavian kingdoms. Nieberding et al. (2004b) did not include rDNA sequences for their Heligmosomoides samples, making it difficult to be sure that all of their clades represent an interbreeding, panmictic population. However, we sequenced the ITS from $H$. polygyrus from Portugal and found it to be identical to that from worms from the UK, which supports the proposal that all $H$. polygyrus isolates from wood mice are drawn from a single panmictic taxon. We nevertheless suspect that H. p. polygyrus may be paraphyletic or polyphyletic, and may include strains from different hosts and geographical areas which have followed independent evolutionary trajectories in the past but have since coalesced with the amelioration of the periglacial environment following the Last Glacial Maximum. This may be particularly so in southern Europe, where the status of H. p. corsicus from house mice remains unclear. Clearly, the phylogenetic history of $H$.p. bakeri is distinct from that of H.p.polygyrus, and we therefore suggest that the laboratory OTU of Heligmosomoides is raised to full species rank. However, because it is currently impossible to recreate a single phylogenetic history for $H$. polygyrus polygyrus in the sense of Adams (1998), the status of this taxon requires further investigation.

The question remains which name to use for the heligmosomatid from laboratory mice. The simplest 
solution appears to be to raise the current subspecies to specific rank as suggested by Tenora and Barus (2001) and Tenora et al. (2003), based in part on the molecular evidence presented in the current paper. According to this interpretation, the laboratory strain then becomes Heligmosomoides bakeri (DuretteDesset et al. 1972; Tenora and Barus, 2001), while worms from Apodemus sylvaticus remain $H$. polygyrus (Dujardin, 1845). The type description is then that of Durette Desset et al. (1972), and type material (paratypes) is deposited in the United States National Museum Helminthological Collection (USNM tube No. 72184). We appreciate that this proposal does not favour taxonomic stability, as the majority of published papers concern the laboratory model, now to be called H. bakeri. However, this revision is considered to be justified as a name change drastically alters our perception of the host range and degree of specialization of these nematodes. There is some evidence that $H$. bakeri produces immunosuppressive molecules that facilitate long-term survival in the laboratory mouse (Pritchard et al. 1994). A better understanding of the taxonomy and evolution of these worms will lead to a more directed hypothesis-driven approach to analysing the role of immunosuppressive molecules in this genus, potentially an important factor in the speciation of heligmosomatid nematodes.

This work was funded by a Natural Environment Research Council (NERC), UK, Advanced Research Fellowship (NER/J/S/2002/00706) to J.C. We are grateful to Dr Les Chappell and Professor Ian Montgomery for the provision of worms from wood mice caught in Aberdeen and Belfast respectively, and to Professor Edward Sinski, Dr Anna Bajer, and the staff of the University of Warsaw field station at Urwitalt for their hospitality. Finally, we thank Mike Bruford and two anonymous reviewers for their helpful comments on the manuscript.

\section{REFERENCES}

Abu-Madi, M. A., Behnke, J. M., Lewis, J. W. and Gilbert, F. S. (1998). Descriptive epidemiology of Heligmosomoides polygyrus in Apodemus sylvaticus from three contrasting habitats in south-east England. Fournal of Helminthology 72, 93-100.

Abu-Madi, M. A., Pleass, R. J. and Lewis, J. W. (1994). Metabolic labelling of wild and laboratory subspecies of the trichostrongyle nematode Heligmosomoides polygyrus. Veterinary Parasitology 55, 235-243.

Abu-Madi, M. A., Behnke, J. M., Lewis, J. W. and Gilbert, F. S. $(2000 a)$. Seasonal and site specific variation in the component community structure of intestinal helminths in Apodemus sylvaticus from three contrasting habitats in south-east England. Fournal of Helminthology 74, 31-44.

Abu-Madi, M. A., Mohd-Zain, S. N., Lewis, J. W. and Reid, A. P. (2000b). Genomic variability within laboratory and wild isolates of the trichostrongyle mouse nematode Heligmosomoides polygyrus. Fournal of Helminthology 74, 195-201.
Adams, B. J. (1998). Species concepts and the evolutionary paradigm in modern nematology. Fournal of Nematology 30, 1-21.

Anderson, T. J. C. (1995). Ascaris infections in humans from North America: molecular evidence for cross-infection. Parasitology 110, 215-219.

Asakawa, M. (1988). Genus Heligmosomoides Hall, 1916 (Heligmosomidae: Nematoda) from the Japanese wood mice, Apodemus spp. II. A review of the genus Heligmosomoides with the establishment of the phylogenetic lines of known species. Fournal of the College of Dairying 12, 349-365.

Asakawa, M. (1991). Genus Heligmosomoides Hall, 1916 (Heligmosomidae: Nematoda) from Japanese Islands. Helminthologia 28, 155-163.

Asakawa, M. and Ohbayashi, M. (1986). Genus Heligmosmoides Hall, 1916 (Heligmosomidae: Nematoda) from the Japanese wood mice, Apodemus spp. I. A taxonomic study on four taxon of the genus Heligmosomoides from three species of the Japanese Apodemus spp. Fournal of the College of Dairying 11, 317-331.

Audebert, F., Chilton, N. B., Justine, J., Gallut, C., Tillier, A. and Durette-Desset, M. C. (2005).

Additional molecular evidence to support a sister taxon relationship between Heligmosomoidea and Molineoidea nematodes (Trichostrongyloidea). Parasitology Research 96, 343-346.

Avise, J. (2000). Phylogeography. Harvard University Press, London.

Barnard, C. J., Behnke, J. M., Gage, A. R., Brown, H. and Smithurst, P. R. (1998). The role of parasiteinduced immunodepression, rank and social environment in the modulation of behaviour and hormone concentration in male laboratory mice (Mus musculus). Proceedings of the Royal Society of London Series B 265, 693-701.

Behnke, J. M. (1987). Evasion of immunity by nematode parasites causing chronic infections. Advances in Parasitology 26, 1-70.

Behnke, J. M., Keymer, A. E. and Lewis, J. W. (1991). Heligmosomoides polygyrus or Nematospiroides dubius? Parasitology Today 7, 177-179.

Behnke, J. M., Lewis, J. W., Mohd-Zain, S. N. and Gilbert, F. S. (1999). Helminth infections in Apodemus sylvaticus in southern England: interactive effects of host age, sex and year on the prevalence and abundance of infections. Fournal of Helminthology 73, 31-44.

Berry, R. J. (1985). Evolutionary and ecological genetics of the bank vole and wood mouse. In The Ecology of Woodland Rodents (ed. Flowerdew, J. R., Gurnell, J. and Gipps, J. H. W.) Symposium of the Zoological Society of London 55, 1-32.

Blouin, M. S. (2002). Molecular prospecting for cryptic species of nematodes: mitochondrial DNA versus Internal Transcribed Spacer. International Fournal for Parasitology 32, 527-531.

Blouin, M. S., Yowell, C. A., Courtney, C. H. and Dame, J. B. (1997). Haemonchus placei and Haemonchus contortus are separate species based on mtDNA evidence. International Fournal for Parasitology 27, 1383-1387.

Burg, R. W. and Stapley, E. O. (1989). Isolation and characterization of the producing organism. In 
Ivermectin and Abamectin (ed. Campbell, W. C.), pp. 24-32. Springer-Verlag, New York.

Chilton, N. B., Gasser, R. B. and Beveridge, I. (1997). Phylogenetic relationships of Australian strongyloid nematodes inferred from ribosomal DNA sequence data. International Fournal for Parasitology 27, 1481-1494.

Durette-Desset, M. C. (1971). Essai de classification des nematodes Heligmosomes. Correlations avec la Paleobiogeographie des hôtes. Memoires du Musée d' Histoire Naturelle 69, 1-126.

Durette-Desset, M. C. (1985). Trichostrongyloid nematodes and their vertebrate hosts: reconstruction of the phylogeny of a parasitic group. Advances in Parasitology 24, 239-303.

Durette-Desset, M. C., Kinsella, J. M. and Forrester, D. J. (1972). Arguments en faveur de la double origine des nematodes nearctiques du genre Heligmosomoides Hall, 1916. Annales de Parasitologie 47, 365-382.

Excoffier, L., Smouse, P. E. and Quattro, J. M. (1992). Analysis of molecular variance inferred from metric distances among DNA haplotypes : application to human mitochondrial DNA restriction data. Genetics 131, 479-491.

Eyualem, A. and Blaxter, M. (2003). Comparison of biological, molecular and morphological methods of species identification in a set of cultured Panagrolaimus isolates. Fournal of Nematology 35, 119-128.

Folmer, O., Black, M., Hoeth, W., Lutz, R. and Vrijenhoek, R. C. (1994). DNA primers for amplification of mitochondrial cytochrome c oxidase subunit from diverse marine invertebrates. Molecular and Marine Biology and Biotechnology 3, 294-299.

Forrester, D. J. and Neilson, J. T. M. (1973). Comparative infectivity of Heligmosomoides polygyrus (=Nematospiroides dubius) in three species of Peromyscus. Fournal of Parasitology 59, 251-255.

Gasser, R. B., Nansen, P. and Guldberg, P. (1996). Fingerprinting sequence variation in ribosomal DNA of parasites by DGGE. Molecular and Cellular Probes 10, 99-105.

Gasser, R. B., Zhu, X., Beveridge, I. and Chilton, N. B. (2001). Sequence heterogeneity in the second internal transcribed spacer (rDNA) within some members of the Hypodontus macropi (Nematoda, Strongyloidea) complex. Electrophoresis 22, 1076-1085.

Genov, T. and Yanchev, Y. (1981). Morphology and taxonomy of the nematodes of the genera Heligmosomoides Hall, 1916 and Heligmosomum Railliet et Henry, 1909 (Heligmosomidae Cram, 1927) from Bulgaria. Khelmintologiya 12, 8-30.

Gregory, R. D., Montgomery, S. S. J. and Montgomery, W. I. (1992). Population biology of Heligmosomoides polygyrus (Nematoda) in the wood mouse. Fournal of Animal Ecology 61, 749-757.

Hillis, D. M. and Dixon, M. T. (1991). Ribosomal DNA: molecular evolution and phylogenetic inference. Quarterly Review of Biology 66, 411-453.

Hoste, H., Gasser, R. B., Chilton, N. B., Mallet, S. and Beveridge, I. (1993). Lack of intraspecific variation in the second internal transcribed spacer (ITS-2) of Trichostrongylus colubriformis ribosomal DNA. International Fournal for Parasitology 23, 1069-1071.
Hugall, A., Stanton, J. and Moritz, C. (1999). Reticulate evolution and the origins of ribosomal internal transcribed spacer diversity in apomictic Meloidogyne. Molecular Biology and Evolution 16, 157-164.

Kavaliers, M., Colwell, D. D., Braun, W. J. and Choleris, E. (2003). Brief exposure to the odour of a parasitized male alters the subsequent mate odour responses of female mice. Animal Behaviour 65, 59-68.

Keymer, A. E. and Slater, A. F. G. (1990). Animal models and epidemiology. In Hookworm Disease: Current Status and New Directions (ed. Schad, G. and Warren, K. S.), pp. 129-144. Taylor and Francis, London.

Mayer, M. S. and Soltis, P. S. (1999). Intraspecific phylogeny analysis using ITS sequences: insights from studies of the Streptanthus glandulosus (Cruciferae). Systematic Botany 24, 47-61.

Monroy, F. G. and Enriquez, F. J. (1992). Heligmosomoides polygyrus: a model for chronic gastrointestinal helminthiasis. Parasitology Today $\mathbf{8 ,}$ 49-54.

Nieberding, C., Morand, S., Libois, R. and Michaux, J. R. (2004a). A parasite reveals cryptic phylogeographic history of its host. Proceedings of the Royal Society, Series $B$ 271, 2559-2568.

Nieberding, C., Libois, R., Douady, C. J., Morand, S. and Michaux, J. R. (2004b). Phylogeography of a nematode (Heligmosomoides polygyrus) in the western Palaearctic region: persistence of northern cryptic populations during ice ages? Molecular Ecology 14, 765-779.

Posada, D. and Buckley, T. A. (2004). Model selection and model averaging in phylogenetics: advantages of Akaike information criterion and Bayesian approaches over likelihood ratio tests. Systematic Biology 53, 793-808.

Posada, D. and Crandall, K. A. (1998). Modeltest: Testing the model of DNA substitution. Bioinformatics 14, 817-818.

Pritchard, D. I., Lawrence, C. E., Appleby, P., Gibb, I. A. and Glover, K. (1994). Immunosuppressive proteins secreted by the gastrointestinal nematode parasite Heligmosomoides polygyrus. International Fournal for Parasitology 24, 495-500.

Quinnell, R. J. (1992). The population dynamics of Heligmosomoides polygyrus in an enclosure population of wood mice. Fournal of Animal Ecology 61, 669-679.

Quinnell, R. J., Behnke, J. M. and Keymer, A. E. (1991). Host specificity of and cross-immunity between two strains of Heligmosomoides polygyrus. Parasitology 102, 419-427.

Schneider, S., Roessli, D. and Excoffier, L. (2000). Arlequin: a software for population genetics data analysis. Ver 2.000. Genetics and Biometry laboratory, Department of Anthropology, University of Geneva, Switzerland.

Scott, M. E. and Tanguay, G. V. (1994). Heligmosomoides polygyrus: a laboratory model for direct life cycle nematodes of humans and livestock. In Parasitic and Infectious Diseases (ed. Scott, M. E. and Smith, G.), pp. 279-300. Academic Press Inc., New York.

Sites, J. W. and Marshall, J. C. (2004). Operational criteria for delimiting species. Annual Review of Ecology and Systematics 35, 199-227. 
Spurlock, G. M. (1943). Observations on host-parasite relations between laboratory mice and Nematospiroides dubius. Fournal of Parasitology 29, 303-311.

Sukhdeo, S. C., Sukhdeo, M. V. K., Black, M. B. and Vrijenhoek, R. C. (1997). The evolution of tissue migration in parasitic nematodes (Nematoda: Strongylida) inferred from a protein-coding mitochondrial gene. Biological Fournal of the Linnaean Society 61, 281-298.

Swofford, D. L. (2003). PAUP*. Phylogenetic Analysis Using Parsimony (*and Other Methods). Version 4. Sinauer Associates, Sunderland, Massachusetts.

Tenora, F. and Barus, V. (2001). Synonymy of the nematode Heligmosomoides polygyrus (Heligmosomidae) and notes on validity of related species. Helminthologia 38, 176.

Tenora, F., Barus, V. and Prokes, M. (2003). Notes to the species Heligmosomoides polygyrus (Dujardin, 1845) (Nematoda, Heligmosomoidae) parasitizing Rodentia. Acta Universitatis Agriculturae et Silviculturae Mendelianae Brunensis 51, 7-18.

Zhu, X. Q., D’Amelio, S., Palm, H. W., Paggi, L., George-Nascimento, M. and Gasser, R. B. (2002). SSCP-based identification of members within the Pseudoterranova decipiens complex (Nematoda: Ascaridoidea: Anisakidae) using genetic markers in the internal transcribed spacers of ribosomal DNA. Parasitology 124, 615-623. 